\title{
Identifying healthcare actors involved in the adoption of information systems
}

\author{
Vasiliki Mantzana ${ }^{1}$, \\ Marinos Themistocleous ${ }^{1}$, \\ Zahir Irani ${ }^{2}$ and \\ Vincenzo Morabito ${ }^{3}$ \\ ${ }^{1}$ School of Information Systems, Computing and \\ Mathematics, Brunel University, West London, \\ U.K.; ${ }^{2}$ Brunel Business School, Brunel University, \\ West London, U.K.; ${ }^{3}$ Bocconi University and SDA \\ Bocconi School of Management, Milan, Italy
}

\section{Correspondence: \\ Vasiliki Mantzana, School of Information Systems, Computing and Mathematics, Brunel University, West London UB8 3PH, U.K. \\ E-mail: Vasiliki.Mantzana@brunel.ac.uk}

\begin{abstract}
The adoption of information systems in healthcare is no less significant than in any other commercial or caring organisation. The literature on IS adoption in healthcare, makes it clear that the actors involved in the adoption process are almost universally seen as crucial, which matches our research results too. However, how such actors should be identified remains a topic for investigatory work since these are early days in achieving this. We derive and propose a structured method to model how actors might be identified: structured because such a rationale is explicable and such a method is more readily usable when transferred to others. Our structured method, named IGOHcaps, uses a static and then a dynamic step to pull out the individual, group, organisational and human determinants of the critical actors. In this process, the individual actors' differing views emerge which could enable decision-making bodies to produce more robust proposals if they incorporated some of the appropriate views. We discuss the application of IGOHcaps through a hospital case study. While a single case study cannot be a proof, the engagement of the actors was encouraging.

European Journal of Information Systems (2007) 16, 91-102.

doi: 1 0.1 1057/palgrave.ejis.3000660
\end{abstract}

Keywords: information systems (IS); adoption; IGOHcaps method; actors; identification; healthcare

\section{The importance of healthcare actors in IS adoption}

The adoption of information systems (IS) has been described as an organisation's decision to acquire a technology and make it available to the users (Hu et al., 2000). In the healthcare sector, how IS is adopted may be critical when the IS relates to human lives. Such adoption is also affected by multiple actors that have different backgrounds and interests (WileyPaton and Malloy, 2004). Healthcare actors often resist the adoption of IS and it has therefore been suggested that they should carefully managed as their role is important during the adoption process (Chen, 2003).

Clearly if one wishes to 'manage' healthcare actors, they need to be initially defined and identified. Such an identification of the actors will also enable decision makers to better understand actors' views and roles and hence enable more informed decisions regarding the adoption of IS. The definition and systematic identification of healthcare actors has been declared to be an area that requires further research (Vos and Achterkamp, 2006). In the attempt described in this paper to address this issue, we introduce a structured method for actors; identification, which is called IGOHcaps.

Section 2 of this paper reviews the literature and conceptualises a structured method that supports healthcare actors' identification. The research methodology used to test the proposed IGOHcaps method is 
described in Section 3 with Sections 4 and 5 presenting and analyzing the empirical findings. Key lessons learned and implications to theory and practice are then extrapolated and reported on before a concluding section.

\section{Deriving and proposing the IGOHcaps method}

The IGOHcaps method is derived from recommendations made in the literature and consists of a static and dynamic approach. The former focuses on the definition of healthcare actors that can be considered as the first stage of actors identification (Vos \& Achterkamp, 2006). While actors' definitions can assist a better understanding of healthcare actors, such definitions have some limitations. For instance, definitions (a) offer simplistic views of IS (Lyytinen \& Hirschheim, 1987), (b) provide generic lists of actors that are not appropriate for all contexts (Pouloudi \& Whitley, 1997) and (c) do not provide practical guidelines for actors' identification. For that reason, we combined the proposed definition (static approach) with a dynamic step that overcomes these limitations.

\section{Defining healthcare actors (static approach)}

According to Chen (2003), actors have been defined as individuals or organisations that affect or are affected by IS applications. These views are shared by others like Miles \& Huberman (1994), Pouloudi \& Whitley (1997) and Salmivalli \& Nissilä (2004). These categories of actors should be studied during the adoption of a new technology, as it is essential to identify how the IS adoption affects and is affected by human relationships and organisational processes. We recognise the existence of these two lenses (individuals or organisations) but for the purpose of this study we will refer to them as human and organisational. Thus, the following issue that is called the 'Human and Organisational Issue' is proposed for further examination: 'IS adoption in healthcare affects and is affected by human and organisational actors'.

The Human and Organisational Issue contributes towards the understanding of the actors' nature (human and organisational). Such a classification may allow different strategies to be put into practice when focusing on the human or organisational lenses. For instance, different strategies should be applied to support the adoption of IS by hospitals (organisations) and medical staff (human actors). Since this issue focuses on the nature of actors (human and organisational), further research should be conducted to identify the main actors' categories. In doing so, we reviewed the literature and identified practical efforts that can support the classification of actors into more detailed categories. These efforts are summarised below:

- The National Health Service (NHS), in the U.K., published a report that presented the benefits of Electronic Health Care Records (EHCR) on different actors (NHS, 1993). The report identified three different 'worlds' that will be affected by EHCR use. In particular, worlds (categories) of actors were identified as: (a) patients (patients, next of kin), (b) clinicians (clinicians, non-clinicians, responsible clinician, a health care facility and clinical student) and (c) third parties (controller, technologist, administrator, legal professional).

- Siau et al. (2002) studied the benefits of decision support and internet applications on the different healthcare actors. According to their study, healthcare actors were classified as: (a) providers and (b) consumers. Similarly, to study the Internet use in healthcare organisations, Siau (2003) mentioned that the internet can be used to link hospitals', suppliers' (insurance, pharmaceutical companies), physicians' and patients' operations.

- The impact of IS on pharmaceutical companies has been studied in relation to actors. The researchers initially identified empirically which actors interact with IS. The actors had been classified into: (a) payers, (b) providers, (c) practitioners and (d) patients (Houghton, 2002).

Based on these efforts, we propose that the following issue (Actors' Categorisation Issue) should be investigated: 'Healthcare actors can be categorised into: (a) Acceptors, (b) Providers, (c) Supporters and (d) Controllers'. We suggest that the combination of the Human and Organisational and the Actors' Categorisation Issues can be used to define healthcare actors. Based on this combination, a definition for healthcare actors (Actors' Definition Issue) is offored for further discussion: 'The healthcare actors involved in the adoption of IS can be defined as: any human and/or organisation that accepts, provides, supports or controls healthcare services'.

As discussed in the beginning of this section, the proposed definition (Actors' Definition Issue) can be considered as the first step towards the development of IGOHcaps structured method for the identification of healthcare actors. Based on the aforementioned limitations, it can be characterised as static, as it identifies a standard number (four) of human and organisational categories of healthcare actors. In an attempt to overcome these limitations, we propose a more detailed and dynamic identification of the actors participating to the IS adoption process. According to Pouloudi (1998), actors' identification should be dynamic, iterative and interpretive. Such a dynamic approach will address respectively, the unsteadiness of organisational reality, the changing roles of actors and the multiple perceptions about actors and their roles. Therefore, we suggest the following Mix ApproachIssue for further investigation: 'The static and dynamic approaches can be combined to support the identification of healthcare actors'

\section{Identifying healthcare actors (dynamic approach)}

IGOHcaps seeks to define, categorise and provide the guidelines to support the identification of healthcare actors in a dynamic healthcare environment. This section 
focuses on the dynamic approach (guidelines) to support the identification of healthcare actors and it is grounded on the published literature.

During the last two decades some efforts have been made to identify healthcare actors. These are based on the principles introduced by Pouloudi \& Whitley (1997) or the dimensions proposed by Lyytinen \& Hirschheim (1987). We acknowledge that both principles and dimensions support the identification of actors. However, we suggest that these two efforts should be combined as the exclusive use of the one or the other effort may not capture all the healthcare actors. Since these efforts were explained and analysed in the literature, it is not our intention to explain them. The combination of the aforementioned efforts leads to the proposition of the Guidelines Issue: 'The guidelines presented in Table 1 support the actors' identification during the dynamic step'.

Table 2 summarises the issues proposed in this section for investigation. These issues are considered as the main constructs of the proposed method for the identification of healthcare actors involved in IS adoption (Figure 1).

The IGOHcaps method is presented in Figure 1 and indicates that healthcare actors involved in the adoption process can be defined (Actors' Definition Issue) as any human and/or organisation (Human and/or Organisational Issue) that accepts, provides, supports and controls (Actors' Categorisation Issue) healthcare services (static step). This static step should be combined with the dynamic to enhance the actors' identification process (Mix Approach Issue). The dynamic step consists of a set of guidelines (Guidelines Issue) that can be used to identify a full range of actors.

When applying this method, the static step (definition) should be considered before the dynamic. Then each of the guidelines should be applied to each of the proposed human and/or organisational categories (static step) individually (e.g. human acceptors, human supporters, etc.). In doing so, a list of healthcare actors will be identified.

\section{Research methodology}

Many research strategies and methodologies can be applied to test the IGOHcaps method. For the purpose of this study, a case-based strategy through the employment of qualitative research methods was considered as it supports the investigation of: (a) little known phenomena (e.g. actors identification in healthcare) and (b) complex processes (IS adoption) in their natural setting. A qualitative case-based strategy, can offer a 'holistic' view of the processes involved, as well as a realisation of the topic under research (Zmud et al., 1989).

A suitable research methodology that acts as the blue print for the research process has been developed. This research methodology is based on three stages namely:

Table 1 Proposed guidelines for healthcare actors identification

\begin{tabular}{|c|c|c|}
\hline Proposed guidelines for healthcare actors' identification & Proposed by & Used in the healthcare area by: \\
\hline \multicolumn{3}{|l|}{ Principles } \\
\hline \multirow{2}{*}{ G1: Actors depend on the specific context and time frame } & \multirow[t]{5}{*}{ Pouloudi \& Whitley (1997) } & Hu et al. (2000) \\
\hline & & Lapointe et al. (2002) \\
\hline G2: Actors cannot be viewed in isolation & & Hu et al. (2000) \\
\hline G3: The position of each actor may change over time & & Mantzana \& Themistocleous (2004) \\
\hline G4: Feasible options may differ from the actors' wishes & & Mantzana \& Themistocleous (2005) \\
\hline \multicolumn{3}{|l|}{ Dimensions } \\
\hline G5: The nature of the IS to be adopted & \multirow[t]{6}{*}{ Lyytinen \& Hirschheim (1987) } & Menachemi et al. (2004) \\
\hline G6: Internal vs external actors & & Mantzana \& Themistocleous (2005) \\
\hline G7: The type of relationship to the system & & Menachemi et al. (2004) \\
\hline G8: Depth of impact & & Menachemi et al. (2004) \\
\hline \multirow[t]{2}{*}{ G9: Level of aggregation } & & Lapointe et al. (2002) \\
\hline & & Gagnon et al. (2004) \\
\hline
\end{tabular}

Table 2 Proposed issues for investigation

\begin{tabular}{ll}
\hline Issue & Description \\
\hline Human and Organisational & IS adoption in healthcare affects and is affected by human and organisational actors \\
Actors' Categorisation & Healthcare actors can be categorised into: (a) Acceptors, (b) Providers, (c) Supporters and (d) Controllers \\
Actors' Definition & The healthcare actors involved in the adoption of IS can be defined as: 'any human and/or organisation \\
& that accepts, provides, supports or controls healthcare services' \\
Mix Approach & The static and dynamic approaches can be combined to support the identification of healthcare actors \\
Guidelines & The guidelines presented in Table 1 support the actors' identification during the dynamic step \\
\hline
\end{tabular}




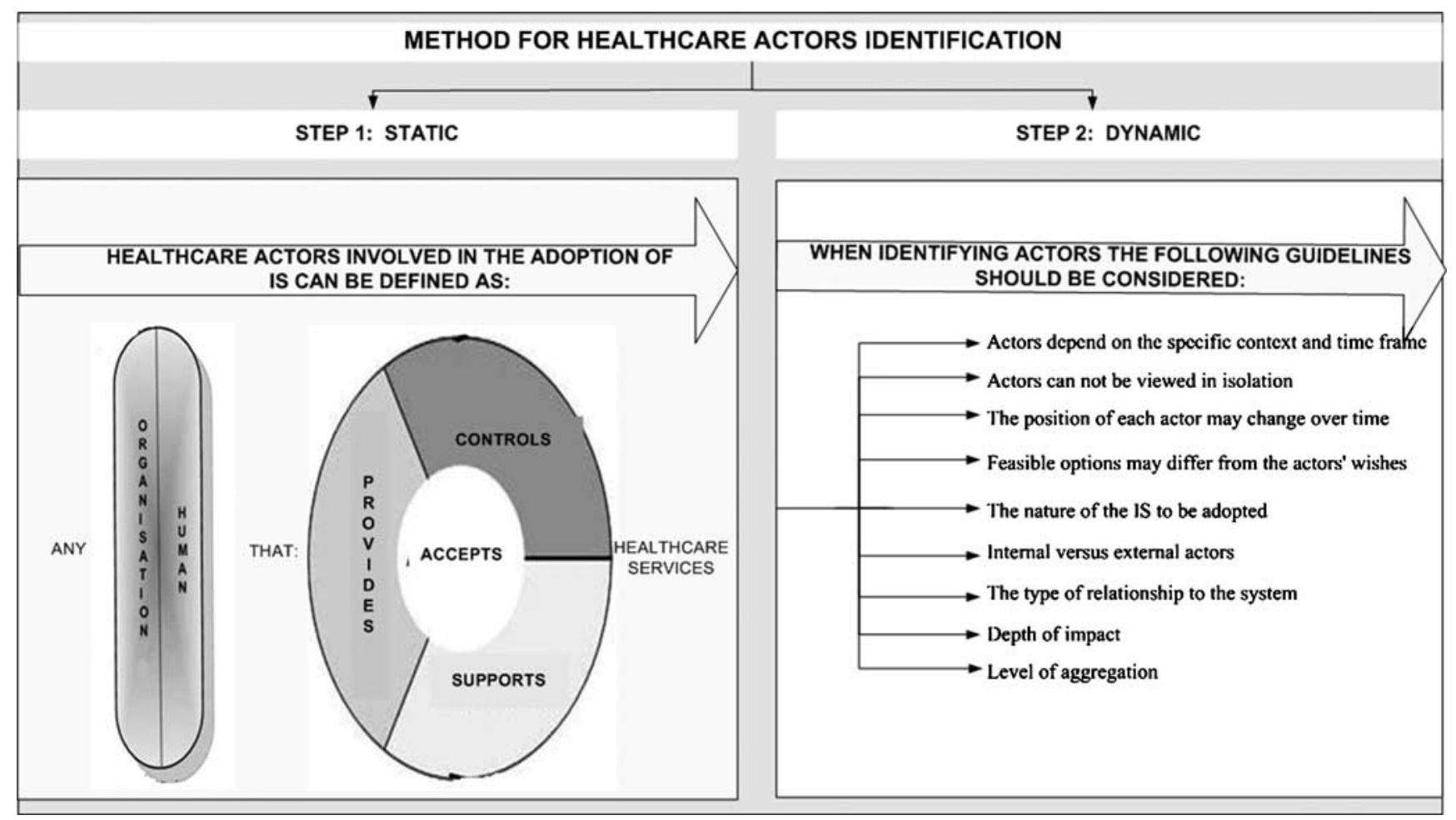

Figure 1 Proposed method (IGOHcaps) for healthcare actor's identification.

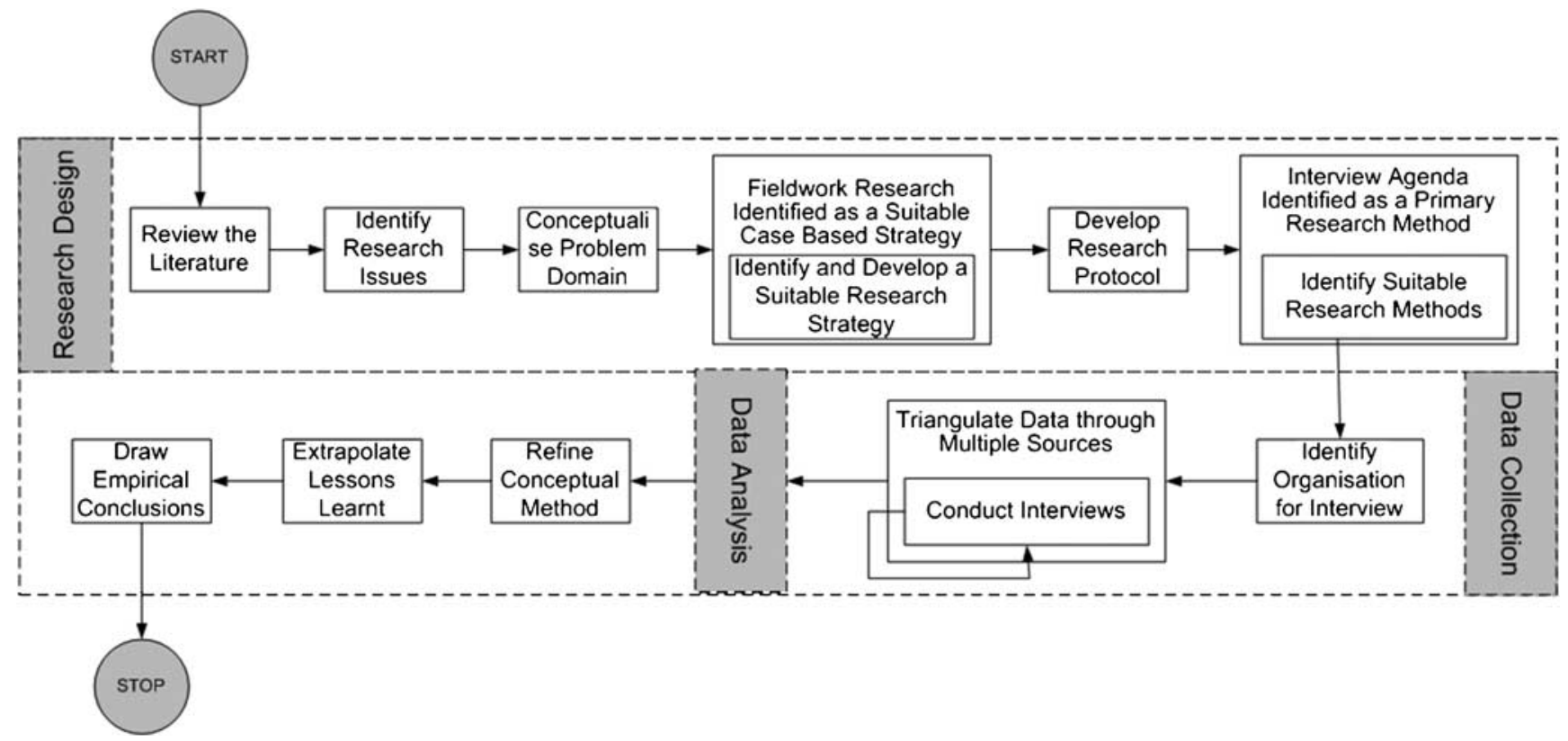

Figure 2 Research methodology.

(a) research design, (b) data collection and (c) data analysis. The research design proposed is the first independent part of the empirical research methodology (illustrated in Figure 2). The starting point is to review the literature, thus developing an understanding of the research that has been done and to identify a suitable void. From the literature review, several research issues emerged for a more focused study on IS adoption in healthcare. This led to a specific research area and identified a research need. A conceptual method was 
then developed. The research design was then transformed into a plan of action or protocol. Research protocols were necessary for the following reasons:

- to put the task of data gathering in a manageable format,

- to ensure that targeted data is collected,

- to ensure that the research follows a specific schedule,

- to track the path at which knowledge was developed and

- to act as a map that others may follow to achieve similar conclusions. This is especially needed, where the issues under investigation are subjective, and depend on qualitative methods.

Within the protocol, a qualitative research method was developed to gather data as required by the units of analysis. The method was in the form of an interview agenda, which is a series of questions, related to the units of analysis, and designed to guide us, during the interviews' process. In addition to the interviews, data were collected through several sources such as archival documents, minutes for meetings, consultancy reports and the website of the organisation. The use of multiple data collection methods supports triangulation and provides stronger substratum of theory (Eisenhardt, 1989). For the purpose of this paper, three types of triangulation were used namely: (a) data (Denzin, 1978), (b) methodological and (c) interdisciplinary triangulation (Janesick, 2000).

In this paper, face-to-face, semi-structured interviews were conducted with different actors. We had a $45 \mathrm{~min}$ discussion with the different actors, to identify if IGOHcaps method is underlined by the issues under investigation. All interviews were tape-recorded and transcripts prepared as soon as possible after each individual interview. Tape recording supported us in collecting data and for its analysis. Taking notes during the interviews simply reduces the time of interviews since notes taking requires more time, thus, we considered tape recording as a more effective way of conducting interviews. The availability of interviewees was a problem during this study, since they had demanding schedules.

\section{The case of HOSP_U.K.}

HOSP_U.K. hospital is a specialised acute trust in the U.K. that was used to test the proposed method. HOSP_U.K. consists of four divisions and nine departments and has more than 1000 employees, in 11 sites. Each employee, service and department belongs to one of these four divisions. The management team comprises of the Chief Executive Officer (CEO), who heads the HOSP_U.K. and the nine departmental directors (e.g. Director of Finance, Director of Nursing and Development).

The existing Information Technology (IT) infrastructure has caused numerous problems, such as the lack of integration of primary, secondary and tertiary services, and lack of communication between the trust and its patients from admission to discharge. Consequently, the delivery of quality services and care was not adequate and resulted in dissatisfied patients and employees. The limitations of the existing applications motivated HOSP_U.K. to improve its IT infrastructure. This decision was supported by the U.K. Commission for Health Improvement (CHI) and it has been in accordance with the U.K.'s healthcare sector modernisation efforts that are taking place. The analysis of relevant documents that were collected during the case indicates that the U.K. government through the U.K. National Health Service Care plan, has focused on the development of an essential patient-centric IS. The key objectives of the NHS plan is to efficiently and effectively provide patients care, based on an integrated IT infrastructure (Wanless et al., 2002; DoH, 2004).

In 2003, HOSP_U.K. initiated a plan for developing a more efficient IT infrastructure, to address the limitations of its existing systems and to meet the targets set by the NHS. The decision for this plan was made by the managing board after discussing with the IT manager. In doing so, HOSP_U.K. decided to develop an integrated patient-centric IT infrastructure and keep the health professionals up to date informed in their practices.

Since HOSP_U.K. admitted limited knowledge on IS integration, it turned to consultants for support in terms of solution development and training. The consultants suggested that the hospital should rely on Enterprise Application Integration (EAI) technology to build the proposed integrated IT infrastructure (Daniel \& White, 2005; Volkof et al., 2005). Moreover, they proposed the development of a pilot project to assess: (a) the performance and efficiency of EAI and (b) the various organisational and managerial parameters associated with its adoption (e.g. restructuring, costs, benefits) (Lam, 2005; Khoumbati et al., 2006). The aim of the pilot project was to demonstrate that EAI supports the development of an efficient, flexible, reliable and maintainable IT infrastructure. The pilot lasted for one year (2003-2004) and during this period the solution was implemented, tested, used and evaluated. As reported by interviewees, the pilot system provided benefits such as technical (sharing of critical data and provision of quality information), managerial (improved communication), operational (reduced operation and maintenance cost) and strategic (increased patients satisfaction).

The pilot system was successful, and as a result the hospital agreed to develop a complete EAI solution. Again, HOSP_U.K. turned to consultancy support due to its lack of technical knowledge (Lam, 2005). Despite the success of the pilot system, it cannot be argued the same for the system that is under implementation. It became apparent that the case organisation did not consider the critical role of the actors involved in the adoption of the EAI solution. The empirical data illustrate that these actors were not informed about the changes associated with the EAI project. In support of this the project manager reported: 'We may have to address a lot of problems when the system is finished. We have not made any discussion 
with the clinicians and other professionals. We estimated that we need to spend around 20,000 staff hours for training after the implementation. Currently the clinicians are not aware of this. Staff is too busy... and the question is when this training will take place. We have not informed them [clinicians] about the changes to their processes and services that this project brings'.

Empirical evidences indicate that the changes associated with this project have not been understood by the multiple actors. The case data also reveal that actors' reaction towards EAI adoption is unclear and may form a risk for the project. These findings are in accordance to the published literature (Lim et al., 2005). When we asked the project manager to comment on these observations he reported that: 'These issues may result in conflicts and resistance to change. We have to find a way to control people's reaction. In our area the consensus of professionals is of high importance as all are significant for the operation of the hospital. For instance, if nurses decide to boycott the new system, the system will be out of order'.

These concerns indicate that it is of high importance to study and analyse the actors' views since their actions can have a great impact on IS adoption. These comments are in line with the literature which highlights that actors' reactions might lead to IS failure (e.g. London Ambulance System) (Fitzgerald \& Russo, 2005).

\section{Application and testing of the IGOHcaps method} In order to identify and study healthcare actors, the IGOHcaps method presented in Figure 1 was introduced and evaluated through the empirical data collected from this case organisation. Initially, we applied and tested the static step of the proposed method that defines and classifies healthcare actors into main categories. The validation of this step is important for the application of the method as the dynamic approach is grounded on the static step. This means that before the application and testing of the dynamic step, the static one must be tested. After the validation of the static step, we used the Guidelines Issue to identify a list of healthcare actors that are involved in the adoption of IS. Thereafter, we assess the guidelines, the list of actors identified and the combination of static and dynamic steps (Mix Approach Issue). The IGOHcaps method and its application were evaluated by the interviewees with the main findings being presented in the next section.

\section{Application and testing of the static step}

To apply and test the static step the interviewees were initially asked to comment on the use of Human and Organisational Issue and the proposed classification (Actors' Categorisation Issue) to define healthcare actors (Actors' Definition Issue). From the discussions, it appeared that all interviewees were positive towards these issues. Regarding Human and Organisational Issue, a clinician (doctor) mentioned that: 'It is good to see that you separate the human actors from the organisational because in many cases human actors express different views from their organisations'. The same person gave as an example, the case of clinicians and clinics as he reported that: 'There are instances where we [doctors-humans] disagree with the suggestions of our clinics [organisational] in terms of the use of $I T^{\prime}$.

An interesting issue came out during the interviews is that humans and organisations should not only be seen individually but also as groups (of people or organisations) [Individuals and Groups sub-lenses]. For example, a clinician might have a different stance towards the adoption of a system, than a group (or different groups) of clinicians. Based on this finding the Human and Organisational Issue should be amended to reflect this differentiation (sub-lenses). In addition, we suggest that further issues such as power, control, legitimacy and influence might be related to the formulation of opinions of these individuals and groups.

The interviewees found the proposed classification of actors into acceptors, providers, suppliers and controllers (Actors' Categorisation Issue) as a satisfactory one. Therefore, they reported that there is no need to extend or revise this classification as they characterised it as complete and representative. For instance, a healthcare manager reported that: 'Your categorisation [Actors' Categorisation Issue] is clear and captures all different groups of actors in healthcare'.

Our empirical evidence shows that the static approach describes the types (lenses) and the categories of healthcare actors involved in the adoption of IT. As Actors' Definition Issue is based on the combination of Human and Organisational and Actors' Categorisation Issues, it appears that healthcare actors can be defined: as any human and/ or organisation that accepts, provides, supports and controls healthcare services (Actors' Definition Issue). In addition, we suggest that in case the Individual and Groups sub-lenses (derived during this case study) are validated, the actors' definition should be revised to incorporate this issue as well.

\section{Application of the dynamic step}

After validating the static step the proposed guidelines were applied individually to the four categories (acceptors, providers, supporters and controllers) of the human and/or organisational lenses (e.g. the guidelines were applied to the human acceptor, organisational acceptor, etc.). An example of this is the application of the fifth guideline (related to the nature of IS) to the organisational providers (sub-category). Based on the fifth guideline (G5) the type of IS to be adopted is an EAI solution that will be used to integrate inter- and intra-organisational systems (Table 3). Therefore, the organisational providers identified are the Hospitals and the Medical Departments (both intra- and inter-organisational). Likewise, we applied the rest of the proposed guidelines within the specific case context and timeframe to identify a list of healthcare actors were identified.

Table 3 shows how the guidelines were used to identify healthcare actors, with the first column referring to the 
actors' categories, the second to the Human $(\mathrm{H})$ and Organisational $(\mathrm{O})$ lenses, the third to the actual actors that are identified through the guidelines presented in the columns 4-12. Due to space limitations the guidelines are presented in Table 3 using the abbreviations (G1, $\mathrm{G} 2$, etc.) of Table 1 . The symbol $(\boldsymbol{})$ indicates that the specific actor is identified by the specific proposed guideline, where the symbol (X) shows the opposite.

Table 3 validates our assertion to combine the guidelines G1-G4 and G5-G9 proposed by Pouloudi \& Whitley (1997) and Lyytinen \& Hirschheim (1987), respectively. As illustrated in Table 3, the actor insurance companies could not be identified using the guidelines proposed by Pouloudi \& Whitley (1997). However, this actor can be identified through the guidelines G5-G9 introduced by Lyytinen \& Hirschheim (1987). Similarly, the actor Next of Kin was only identified using the guidelines G1-G4.

After identifying the list of healthcare actors, the Actors' List Issue has arisen: 'The list of healthcare actors presented in Table 3 is complete and representative, in the specific time frame and context'. Figure 3 illustrates the outcome of the proposed method's application as it was explained in Table 3 and analysed in this section.

\section{Testing the actors' list issue}

Initially, the interviewees were asked to comment on the proposed list of healthcare actors presented in Figure 3. From the discussions we had with the interviewees it appears that two new actors do exist. Also, the interviewees expressed a different point of view regarding the actor Manager.

More specifically, it has been reported by a Clinician that 'patients should be differentiated from the Citizens'. In support of this, various European Union (EU) plans report that the focus of healthcare should not be on how to provide treatment to patients but on minimising the percentages of people that need treatment. In doing so, the healthcare should improve Citizens' quality of life. It appears that the Citizens could not be identified by the use of the proposed guidelines (see Table 1). This is attributed to that we contacted the interviewees in different time periods. During the first round of field work visits, the information about the citizens was not

Table 3 Actors identification through IGOHcaps method

\begin{tabular}{|c|c|c|c|c|c|c|c|c|c|}
\hline & \multicolumn{9}{|c|}{ Proposed guidelines } \\
\hline & G1 & G2 & G3 & G4 & G5 & G6 & G7 & G8 & 69 \\
\hline \multicolumn{10}{|l|}{ Acceptor } \\
\hline \multicolumn{10}{|l|}{$\mathrm{H}$} \\
\hline Patients & $\nu$ & $\nu$ & 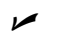 & 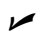 & 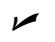 & $\nu$ & 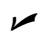 & 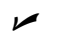 & $\nu$ \\
\hline Next of kin & $X$ & $\nu$ & 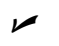 & $X$ & $X$ & $X$ & $X$ & $x$ & $X$ \\
\hline \multicolumn{10}{|l|}{ Provider } \\
\hline \multicolumn{10}{|l|}{$\mathrm{H}$} \\
\hline Clinicians & レ & $\nu$ & $\swarrow$ & $\nu$ & $\nu$ & $\nu$ & $\nu$ & レ & 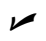 \\
\hline Non-clinicians & 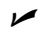 & 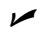 & 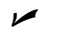 & $\nu$ & $\nu$ & $\nu$ & $\nu$ & レ & 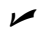 \\
\hline Clinical students & $X$ & $x$ & 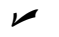 & $X$ & $\nu$ & 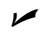 & $\nu$ & レ & 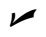 \\
\hline \multicolumn{10}{|l|}{$\mathrm{O}$} \\
\hline Hospitals & $\nu$ & 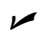 & $x$ & $\nu$ & $\nu$ & $\nu$ & $\nu$ & 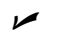 & 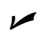 \\
\hline Medical departments & 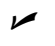 & 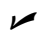 & $x$ & 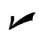 & 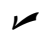 & $\nu$ & $\nu$ & 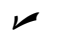 & 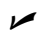 \\
\hline \multicolumn{10}{|l|}{ Supporter } \\
\hline \multicolumn{10}{|l|}{$\mathrm{H}$} \\
\hline Administrators & $\nu$ & $\nu$ & 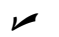 & $X$ & $\nu$ & $\nu$ & $\nu$ & 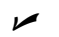 & $\nu$ \\
\hline Legal professionals & $X$ & $\nu$ & 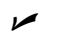 & $x$ & 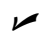 & $\nu$ & $\nu$ & 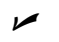 & $\nu$ \\
\hline Researchers & $x$ & $x$ & 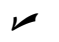 & $x$ & 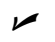 & $\nu$ & 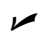 & 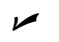 & $\nu$ \\
\hline \multicolumn{10}{|l|}{$\mathrm{O}$} \\
\hline Suppliers & $\nu$ & $\nu$ & $x$ & $\nu$ & $\nu$ & $\nu$ & $\nu$ & レ & $\nu$ \\
\hline Technologists & $\nu$ & $\nu$ & $x$ & 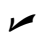 & 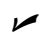 & $\nu$ & $\nu$ & & 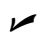 \\
\hline Insurance companies & $X$ & $X$ & $x$ & $X$ & $\nu$ & $\nu$ & $\nu$ & 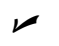 & $\nu$ \\
\hline \multicolumn{10}{|l|}{ Controller } \\
\hline \multicolumn{10}{|l|}{$\mathrm{H}$} \\
\hline Managers & 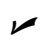 & $\nu$ & 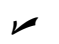 & 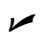 & $\nu$ & 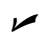 & 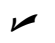 & 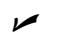 & $\nu$ \\
\hline \multicolumn{10}{|l|}{$\mathrm{O}$} \\
\hline Government & 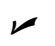 & 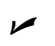 & $x$ & $\nu$ & $\nu$ & $\nu$ & $\nu$ & レ & 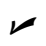 \\
\hline Health authorities & $\nu$ & $\nu$ & $x$ & 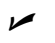 & 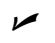 & 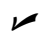 & 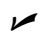 & & 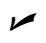 \\
\hline
\end{tabular}




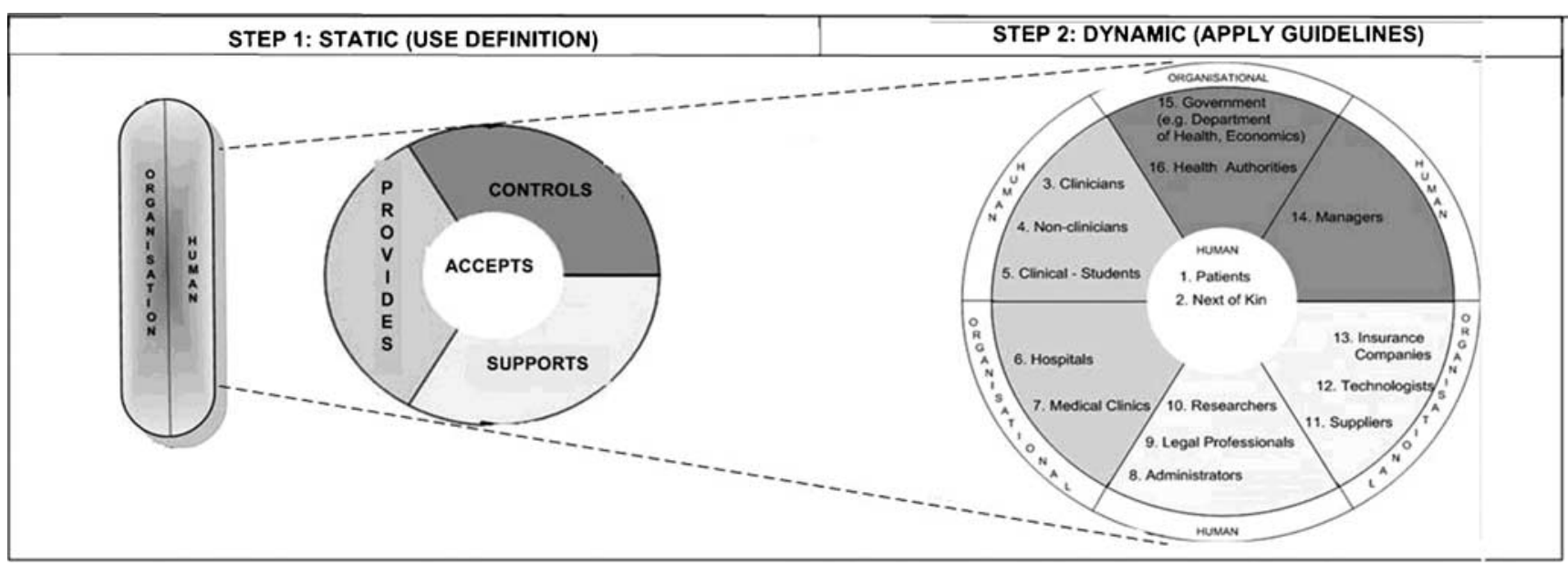

Figure 3 List of healthcare actors derived through the application of IGOHcaps method.

available. When we revisited the HOSP_U.K. a couple of months later, the patients had been separated from the citizens by the EU plans and directions. Although we failed to identify the actor Citizen, the guidelines covered this issue as G1 suggests that the actors depend on the specific context and timeframe.

Apart from the actor Citizen, the $66 \%$ of interviewees from different actors' categories mentioned that other actors exist such as the Bank. Also, from the empirical data it reveals that the various actors should be analysed in more detail. For instance, in the proposed taxonomy (in Table 3), the actor Manager (in the category Controller) represents all managers at all levels. Nonetheless, this is not accurate in terms of analysis, as diverse categories of managers exist with different interests (e.g. IT Manager, Clinicians' Manager, Finance Manager).

\section{Testing the guidelines and the mix approach issues}

When we tested the proposed guidelines (presented in Table 1), we realised that they have a limitation as they omit the information regarding the business processes. As a result, we suggest that the following guideline should be considered and tested when identifying actors: The business processes should be considered when identifying different actors. The reason behind this suggestion is that the adoption of IS aims to automate business processes. Thus, human and organisational actors (internal or external) related to these processes should be studied as they affect or are affected by the adoption of a system. This finding is significant as it has not been reported on before.

As it is explained above, the static and the dynamic steps were validated, with empirical evidences suggesting the addition of: (a) the Individual and Group sub-lenses and (b) one new guideline. Despite these findings the interviewees mentioned that the Mix Approach enhance the understanding, identification and classification of healthcare actors. Therefore, the Mix Approach Issue was validated by the interviewees as it is illustrated in Table 3 and Figure 3.

\section{Discussion and lessons learnt}

\section{Findings and revised IGOHcaps method for healthcare actors identification}

The empirical investigation indicates that the proposed method can be used to identify the healthcare actors involved in the adoption process. From the discussions with the interviewees few additional findings related to the actors' identification arose. These findings are summarised below and presented in Table 4. It was revealed that all issues under examination were validated. Moreover, the case data uncovered additional attributes of Human and Organisational, Actors' Definition, Guidelines and Actors' List Issues.

- Human and Organisational Issue: Sub-lenses should to be used to distinguish individuals from groups of human and organisational actors.

- Actors' Definition Issue: Healthcare actors involved in the adoption of IS can be defined as: 'any individual or group of human and/or organisation that accepts, provides, supports or controls healthcare services'.

- Guidelines Issue: One new guideline derived for healthcare actors identification involved in the adoption of IS: 'The business processes should be considered as another guideline when identifying different actors'. It seems that this guideline may be used to identify not only the healthcare actors that are involved in the adoption of IS but it can be used in other environments as well. However, this issue should be further explored and tested.

- Actors' List Issue: In addition to the actors identified in Table 3, the actors Banks and Citizens should be considered as well. Also, different types of the actor Manager should be identified and tested.

The findings that emerged from the case data and discussed above, have been taken into consideration. In doing so, we propose a revised method for the identifica- 
Table 4 Stages of empirical investigation and main findings

\begin{tabular}{|c|c|c|c|c|c|c|}
\hline $\begin{array}{l}\text { Stage of empirical } \\
\text { investigation }\end{array}$ & Research issue & Defined & Applied & Tested & Validated & Findings \\
\hline 1 & Human and Organisational Issue & & & $\boldsymbol{}$ & レ & $\begin{array}{l}\text { Sub-lenses should be used to distin- } \\
\text { guish individuals from groups of hu- } \\
\text { man and organisational actors }\end{array}$ \\
\hline 2 & Actors' Categorisation Issue & & & $\boldsymbol{}$ & レ & \\
\hline 3 & Actors' Definition Issue & & & レ & レ & $\begin{array}{l}\text { Healthcare actors involved in the } \\
\text { adoption of IS can be defined as: 'any } \\
\text { individual or group of human and/or } \\
\text { organisation that accepts, provides, } \\
\text { supports or controls healthcare ser- } \\
\text { vices' }\end{array}$ \\
\hline 4 & $\begin{array}{l}\text { Human and Organisational, Actors' } \\
\text { Categorisation, Actors' Definition, } \\
\text { Guidelines and Mix Approach Issues }\end{array}$ & & レ & & & $\begin{array}{l}16 \text { actors were identified (see Table } \\
\text { 3) }\end{array}$ \\
\hline 5 & - & $\begin{array}{l}\text { Actors' List } \\
\text { Issue }\end{array}$ & & & & 16 actors to be tested \\
\hline 6 & Mix Approach Issue & & & レ & レ & \\
\hline 7 & Guidelines Issue & & & $\boldsymbol{V}$ & レ & \\
\hline 8 & Actors' List Issue & & & $\boldsymbol{\nu}$ & レ & \\
\hline 9 & - & $\begin{array}{l}1 \text { New } \\
\text { Guideline }\end{array}$ & & & & $\begin{array}{l}\text { The business processes should be } \\
\text { considered when identifying different } \\
\text { actors. This guideline should be } \\
\text { tested }\end{array}$ \\
\hline 10 & - & 2 New Actors & & & & Banks and Citizens were identified \\
\hline 11 & & $\begin{array}{l}\text { Diverse types } \\
\text { of managers }\end{array}$ & & & & $\begin{array}{l}\text { The different types of actor Manager } \\
\text { should be identified and tested }\end{array}$ \\
\hline
\end{tabular}

tion of healthcare actors. The revised IGOHcaps method is illustrated in Figure 4.

\section{Lessons learnt}

As reported above, we studied the area of IS adoption in healthcare and sought to understand the process of actors identification. No claim for generalisation is made for interpretive research of this type. Thus, the lessons learnt are a result of the description provided and do not seek to be prescriptive. These lessons might be helpful to healthcare organisations as well as to researchers and IT practitioners and are summarised below:

Lesson 1 Healthcare actors have an important role during the decision-making process for IS adoption. This crucial role has been reported in the literature and was validated through this research. Within the context of healthcare organisations it appears that the role of actors is more significant than expected, as some actors (e.g. nurses, clinicians) seem to have the power to hold back the adoption or even lead to system's failure.

Lesson 2 Since not all the members of one actors' category share the same views, it is suggested that Individual and Group sub-lenses should be used in combination to the human and organisational lenses to further distinguish actors. This helps organisations to better understand and analyse the reactions of actors.

Lesson 3 When exploring the Individual and Group sub-lenses, issues of power, control and legitimacy should be considered. These issues are of high importance, as they influence Individuals and Groups of actors towards the IS adoption.

Lesson 4 The proposed method for the identification of healthcare actors (Figure 1) seems to have a limitation since it cannot support the identification of sub-categories of some actors. Thus, we suggest that a new guideline related to the business process has to be used. In doing so, the different sub-categories of actors will be identified (e.g. managers: IT manager, clinicians' managers, etc.).

Lesson 5 The IGOHcaps method proposed and tested in this paper provides some advantages when comparing with the guidelines proposed by Pouloudi \& Whitley (1997) and Lyytinen \& Hirschheim (1987). For instance, the proposed method provides a structured way to identify healthcare actors and classifies them into different categories (e.g. acceptors) and lenses (human and organisational). On the contrary, the guidelines proposed by Pouloudi \& Whitley (1997) and Lyytinen \& Hirschheim (1987) can be used to identify a laundry list of actors. 


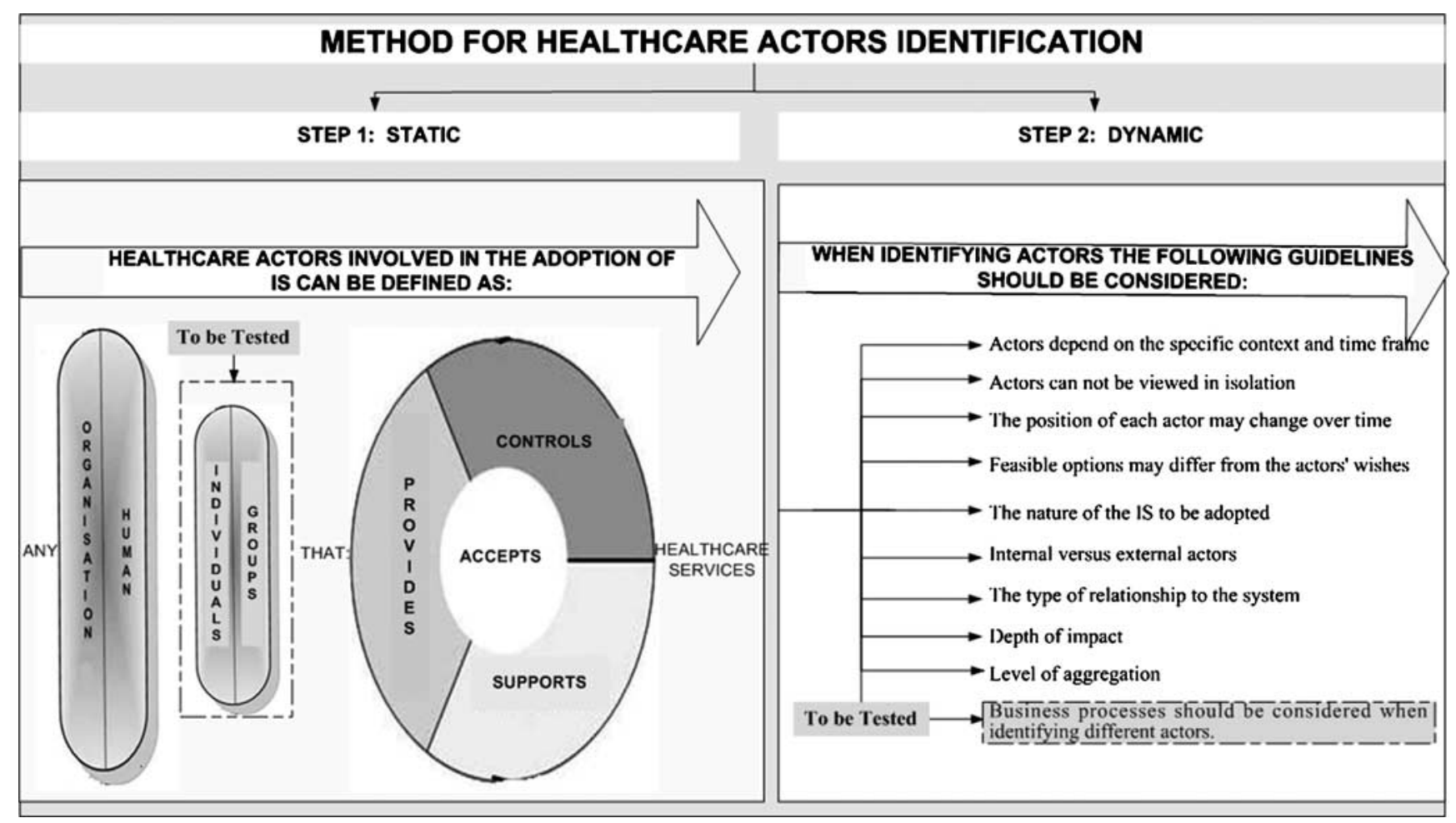

Figure 4 Revised IGOHcaps method for the identification of healthcare actors.

Furthermore, as we proved in this paper, we can identify more actors by combining the guidelines proposed by Pouloudi \& Whitley (1997) and Lyytinen \& Hirschheim (1987) instead of using them individually. Thus, IGOHcaps method leads to more systematic way to identify healthcare actors and can enhance the level of analysis and understanding.

\section{Conclusions and contribution}

Despite the multiple adoption models that have emerged and widely applied in healthcare organisations, IS adoption remains a slow and problematic process. To improve the IS adoption, we propose to examine the role of actors during the adoption process, as their importance has been widely recognised. This paper introduces the IGOHcaps method for actors' identification, which consists of a static and dynamic step. The static one defines and categorises the healthcare actors into human and organisational acceptors, providers, controllers and supporters. The dynamic step consists of a set of guidelines that can be used to systematically refine the actors. To evaluate the conceptual method, the healthcare actors related to the Enterprise Application Integration adoption were identified and categorised. The empirical data reveal that within the specific case organisation 18 actors are involved in the adoption process.

The IGOHcaps method makes a novel contribution at both the practical and conceptual level. At a practical level, the model contributes towards a deeper understanding of the actors in healthcare organisations. At the conceptual level, it proposes a method for healthcare actors' identification that should be considered during the adoption of IS in healthcare. The proposed IGOHcaps method increases the level of the analysis and contributes towards a more detailed and systematic study of the adoption of IS in healthcare sector. Moreover, it supports managers and researchers in: (a) understanding the importance and effect of healthcare actors, (b) supports the identification of the multiple healthcare actors and (c) might increase the adoption of IS in healthcare.

\section{Further work and research limitations}

Although the case data validated the proposed method, the following propositions have been made for further research:

- The revised IGOHcaps method presented in Figure 4 should be tested. In doing so the issues resulted from this research such as the sub-lenses and the new guideline should be examined.

- The roles and interrelationships of the different actors should be studied over time and over the lifecycle of the adoption process. This is also in line with the normative literature (Rogers, 1995).

One of the limitations of this research is that the outcomes presented herein are based on a single casebased strategy. Thus, the data and the observations 
derived from this case cannot be generalised. Nonetheless, it is not the intention of this paper to offer prescriptive guidelines about which actors are affected and affect the adoption process. The purpose of the paper is to allow others to relate their experiences to those reported herein.

\section{About the authors}

Dr. Vasiliki Mantzana is Research Fellow in the School of Information Systems, Computing and Mathematics at Brunel University. She holds a Ph.D. in the adoption of Enterprise Application Integration in healthcare organisations from Brunel University. She holds an MSc on Telemedicine and e-Health Systems and a Bachelor's degree on Information Systems. She has published several research papers in internationally refereed journals and international conferences such as ECIS, HICSS and AMCIS.

Dr Marinos Themistocleous is a senior lecturer in the School of Information Systems, Computing and Mathematics at Brunel University. He holds a Ph.D. in 'Adopting and Evaluating Enterprise Application Integration' from Brunel University, an MSc on Information Systems Management and a Bachelor's degree in Computer Sciences. He has close relationships with industry and has worked as a consultant for the Greek Ministry of Finance, the Greek Standardization body, the Greek Federation of SMEs, the ORACLE Greece and ORACLE U.K. He has co-authored three teaching textbooks, published more than 20 internationally refereed journal papers and received citations of excellence. He acts as an international reviewer for research proposals submitted to the European Union.

Professor Zahir Irani is the Head of the Business School at Brunel University (U.K.). Having worked for several years as a project manager, he retains close links with industry. He consults for the Office of the Deputy Prime Minister (ODPM) in the U.K. as well as international organisations such as HSBC, Royal Dutch Shell Petroleum, BMW and Adidas. He has also taken part in U.K. Government-funded trade missions to the Middle East and Gulf region. He reviews research proposals submitted to U.K. funding councils, European Commission and the National Science Foundation (NSF) in the U.S.A. He leads a multi-disciplinary group of International Ph.D. students that research information systems evaluation and application integration. He has been recognised as the Hooker Distinguished Professor at McMaster University
(Canada) as well as being a Visiting Professor at several Universities. He is the editor-in-chief of the established Journal of Enterprise Information Management and European Editor of the Business Process Management Journal. He has co-authored teaching textbooks and written almost 200 internationally refereed papers and received ANBAR citations of research excellence. He has spoken at conferences and guest seminars worldwide, and is internationally known for his scholarly work in the area of information systems evaluation and application integration. He is on the editorial board of several journals, as well as co-and-mini-track chair to international conferences. He has edited special issue journals, and publishes his scholarly work in leading journals that include: IEEE Transactions on Engineering Management, Information \& Management, Information Systems Journal, Journal of Management Information Systems and European Journal of Information Systems. He has received numerous contracts, grants and awards from funding bodies that include the Engineering and Physical Sciences Research Council (EPSRC), Economic and Social Research Council (ESRC), Royal Academy of Engineering, Australian Research Council (ARC), QinetiQ, Department of Health and European Commission.

Dr Vincenzo Morabito is Assistant Professor at Bocconi University (Milan, Italy), Organization and Information Systems Department. He has earned a Ph.D. in Management and Business Administration from the same University and currently teaches three courses (Management Information Systems, Organization and Management Information Systems and Database Management Information Systems). His research interest focuses on IT Strategy and Governance, Outsourcing and Information System models and definition. Over the last two years, he has participated as a speaker in several international conferences, including ECIS (European Conference of Information Systems) and the Italian Workshop for Organization and Information System Academic Scholars. He has published numerous papers on ASP, outsourcing of IS and ERP.

\section{References}

CHEN M (2003) Factors affecting the adoption and diffusion of XML and Web services standards for E-business systems. International Journal of Human-Computer Studies 58, 259-279.

DANIEL E and WHITE A (2005) The future of inter-organisational linkages, findings of an international Delphi study. European Journal of Information Systems 14(2), 188-203.
DENZIN NYK (1978) The Research Act: A Theoretical Introduction to Sociological Methods. McGraw Hill, New York, U.S.A.

DOH (2004) The NHSPlan - A Plan for Investment, a Plan for Reform. Stationary Office, London. Available at www.dh.gov.uk/PolicyAndGui dance/OrganisationPolicy/Modernisation/NHSPlan/fs/en?CONTENT_ID = $4082690 \&$ chk $=$ /DU1 UD, accessed on August 2005. 
EISENHARDT KM (1989) Building theories from case study research. Academy of Management Review 14(4), 532-550.

FitzGerald G and Russo NL (2005) The turnaround of the London Ambulance Service Computer-Aided Despatch system (LASCAD). European Journal of Information Systems 14(3), 244-257.

Gagnon M, lamothe L, Fortin J, Cloutier A, Godin G, Gagne $C$ and REINHARZ D (2004) The impact of organisational characteristics on telehealth adoption by hospitals. In Proceedings of Thirty-Seventh Annual Hawaii International Conference on System Sciences (HICSS 37), Big Island, Hawaii, U.S.A., January 5-8 (SPRAGUE RJ, Ed), IEEE Computer Society, Los Alamitos, California, U.S.A. [CD Proceedings].

HOUGHTON J (2002) Information Technology and the Revolution in Healthcare, Center for Strategic Economic Studies, Victoria University of Technology, Melbourne, accessed on 25th August 2004

HU PJ, CHAU PYK and SHENG OL (2000) Investigation of factors affecting healthcare organization's adoption of telemedicine technology. In Proceedings of Thirty-Third Hawaii International Conference on System Sciences (HICSS-33), Big Island, Hawaii, U.S.A., January 4-7 (SPRAGUE RJ, Ed), pp 1-10, IEEE Computer Society, Los Alamitos, California, U.S.A. JANESICK V (2000) The choreography of qualitative research design. In Handbook of Qualitative Research (DENZIN NYK and LINCOLN YS, Eds), pp 379-399, Sage Publications, Thousand Oaks, CA.

KHOUMBATI K, THEMISTOCLEOUS M and IRANI Z (2006) Evaluating the adoption of enterprise application integration in healthcare organisations. Journal of Management Information Systems 22(4), 69-108.

LAM W (2005) Investigating success factors in enterprise application integration: a case-driven analysis. European Journal of Information Systems 14(2), 175-187.

LAPOINTE L, LAMOTHE L and FONTIN JP (2002) The dynamics of IT adoption in a major change process in healthcare delivery. In Proceedings of Thirty-Fifth Annual Hawaii International Conference on System Sciences, (HICSS 35), Big Island, Hawaii, U.S.A., January 7-10 (SPRAGUE RJ, Ed), IEEE Computer Society, Los Alamitos, California, U.S.A. [CD Proceedings].

LIM ETK, PAN SL and TAN CW (2005) Managing user acceptance towards enterprise resource planning (ERP) systems - understanding the dissonance between user expectations and managerial policies. European Journal of Information Systems 14(2), 135-149.

LYYTINEN K and HIRSCHHEIM RA (1987) Information Systems Failures - $a$ Survey and Classification of the Empirical Literature. Oxford University, Oxford.

MANTZANA V and Themistocleous M (2004) Identifying and classifying benefits of integrated healthcare systems using an actor oriented approach. Journal of Computing and Information Technology 2(4), 265-278.

MantZana $V$ and Themistocleous M (2005) Towards a conceptual framework of actors and factors affecting the EAl adoption in healthcare organisations. In Proceedings of 13th European Conference on Information Systems, (ECIS 2005) (Bartman D, Rajola F, KallinikOS ], AVISON D, Winter R, EIN-Dor P, BECKER J, BODENDORF $F$ and Weinhardt $C$, Eds) Regensburg, Germany, May 26-28 [CD Proceedings].

MENACHEMI N, BURKE DE and AYERS D (2004) Factors affecting the adoption of telemedicine - a multiple adopter perspective. Journal of Medical Systems 28(6), 617-632.

MILES MB and HUBERMAN AM (1994) Qualitative Data Analysis: An Expanded Sourcebook. Sage Publications, Thousand Oaks, CA.

NHS (1993) The good European health record: ethical and legal requirements. London. Available at http://www.chime.ucl.ac.uk/workareas/ehrs/GEHR/EUCEN/del8.pdf, accessed June 2004.

POULOUDI A (1998) Stakeholder analysis for interorganisational information systems in healthcare. PhD Thesis, Information Systems, London School of Economics and Political Sciences, London.

POULOUDI A and WHITLEY EA (1997) Stakeholder identification in interorganisational systems: gaining insights for drug use management systems. European Journal of Information Systems 6(1), $1-14$

ROGERS EM (1995) Diffusion of Innovations. The Free Press, New York.

SALMIVALLI L and NISSILä J (2004) Curing health care information systems with open source software. In Proceedings of Twelfth European Conference on Information Systems (AMCIS 2004) (LEINO T, SAARINEN T and KLEIN S, Eds), Turku School of Economics and Business Administration, Turku, Finland.

SIAU K (2003) Health care informatics. IEEE Transactions on Information Technology in Biomedicine 7(1), 1-7.

SIAU K, SOUTHBARD P and HONG S (2002) E-healthcare strategies and implementation. International Journal of Healthcare Technology and Management 4(1/2), 118-131.

VolKof O, STRONG D and ELMES M (2005) Understanding enterprise systems-enabled integration. European Journal of Information Systems 14(2), 110-120.

VOS FJJ and ACHTERKAMP MC (2006) Stakeholder identification in innovation projects: going beyond classification. European Journal of Innovation Management 9(2), 161-178.

WANLESS D, CharlesWorth A, WALKer I, BeCK M, BLACK I, BLUE I, BRINDLE $S$, BUCht C, DunN S, FaIRWEater M, GhazI-Tabatabal Y, INNes D, LeWIS L, PATEL $V$ and YORK N (2002) Securing our Future Health: Taking a LongTerm View. HM Treasury, http://www.hm-treasury.gov.uk/wanless (Day of Access, May 2004).

WILEY-PATON S and MALLOY A (2004) Understanding healthcare professionals' adoption and use of IT. In Proceedings of Tenth Americas Conference on Information Systems, (AMCIS 2004), (GALletTE D and Ross J, Eds), pp 179-183, New York, August 6-8.

ZMUD RW, OLSON MH and HAUSER R (1989) Field experiment in MIS research. In Harvard Business School Research Colloquium (BENBASAT I, Ed). The Information Systems Research Challenge: Experimental Research Methods, 2, pp 97-112. 